\title{
The impact of knowledge management on MNC subsidiary performance the role of absorptive capacity
}

Mahnke, Volker; Pedersen, Torben; Venzin, Markus

Document Version

Final published version

Publication date:

2003

License

CC BY-NC-ND

Citation for published version (APA):

Mahnke, V., Pedersen, T., \& Venzin, M. (2003). The impact of knowledge management on MNC subsidiary performance: the role of absorptive capacity.

Link to publication in CBS Research Portal

\section{General rights}

Copyright and moral rights for the publications made accessible in the public portal are retained by the authors and/or other copyright owners and it is a condition of accessing publications that users recognise and abide by the legal requirements associated with these rights.

Take down policy

If you believe that this document breaches copyright please contact us (research.lib@cbs.dk) providing details, and we will remove access to the work immediately and investigate your claim.

Download date: 26. Apr. 2023 


\section{Working Paper}

\section{The impact of knowledge management on MNC subsidiary performance: the role of absorptive capacity}

By

\section{Volker Mahnke, Torben Pedersen and Markus Venzin}

No. 1-2004

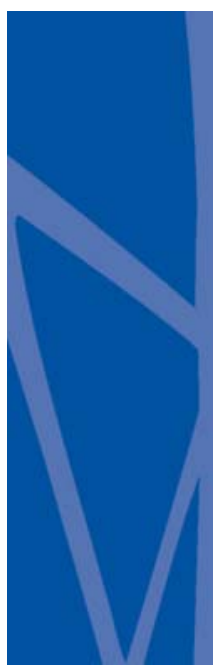

Institut for Informatik

Handelshøjskolen

i København

Howitzvej 60

2000 Frederiksberg

TIf.: 38152400

Fax: 38152401

http://www.inf.cbs.dk
Department of Informatics

Copenhagen

Business School

Howitzvej 60

DK-2000 Frederiksberg

Denmark

Tel.: +45 38152400

Fax: +45 38152401

http://www.inf.cbs.dk 


\title{
The impact of knowledge management on MNC subsidiary performance: the role of absorptive capacity
}

\author{
Volker Mahnke, Torben Pedersen and Markus Venzin
}

Volker Mahnke, Associate Professor, Dep. of Informatics, Copenhagen Business School, Howitzveij 60 (4); 2000 Copenhagen-FDB; vm.inf@cbs.dk, Denmark

Torben Pedersen, Professor, Dep. Of International Management and Economics, Copenhagen Business School, Howitzveij 60 (2); 2000 Copenhagen-FDB; tp.intbs.dk, Denmark

Markus Venzin, Assistant Professor, Dep. Of Strategy, Bocconi University, Via Isonzo 23; 20136 Milano; mvenzin@uni-bocconi.it, Italy 


\begin{abstract}
Empirical studies on the impact of knowledge management on the performance of MNC subsidiaries remain elusive to date. This study examines the effect of knowledge management tools such as corporate university, communities of practice, group benchmarking, learning systems and rewards upon absorptive capacity and performance with unique data from subsidiary units in a large German MNC - Heidelberger Cement. The findings suggest that knowledge management tools unfold their performance impact through their significant influence on absorptive capacity and knowledge inflows. The key contributions to the current literature on knowledge flows in the MNC include an empirically corroborated link between deployments of knowledge management tools and their impact on the subsidiary employee's ability and motivation to learn from internal knowledge flows in the $\mathrm{MNC}$ as well as their impact on subsidiary business performance.
\end{abstract}




\section{Introduction}

This study examined the effect of applying knowledge management tools in subsidiaries on developing absorptive capacity to benefit from internal knowledge flows to improve business performance with unique data from a German MNC - Heidelberger Cement. Knowledge management tools include reward systems, learning system, and communities of practice, group benchmarking report, and corporate university. Proxies measuring subsidiary employee's motivation and ability to learn from knowledge-inflows captured absorptive capacity. Business performance was assed by several dimensions of business performance including economic gains and product development. Knowledge management tools strongly predicted absorptive capacity indicating managerial discretion in the development of a unit's absorptive capacity; absorptive capacity as endogenous variable strongly predicts knowledge inflow and the knowledge inflow predict significantly business performance on a subsidiary level. Findings suggest integration of research on knowledge-flows, absorptive capacity, as well as subsidiary performance and a concomitant stimulant for future research along these lines.

Many authors, picturing the modern MNC as a "differentiated network," have discussed the importance of knowledge flows between subsidiaries for the MNC performance (Bartlett and Ghoshal, 1989; Gupta and Govindarajan, 1991; 2000). However, only a few studies have started to examine this relationship empirically, looking mainly at the effect of antecedence to knowledge sharing and learning in the external (e.g. Lyles and Salk, 1996; Lane and Lubatkin, 1998; Lane, Salk and Lyles, 2001, Simonin, 1999) and internal relations of the MNC (e.g. Gupta and Govindarajan, 2000; Hansen, 1999; Holm and Pedersen 2000; Minbaeva et al, 2003). Common to these studies is that they focus on antecedence of knowledge sharing and assess the level of shared knowledge. However, with a few exceptions like Andersson et al. (2002) the relation between knowledge flows and subsidiary performance remains largely asserted rather than empirically corroborated. This study addresses the performance implications of knowledge flows in the MNC directly.

Several studies on the MNC knowledge flows propose that the absorptive capacity of the receiving unit is the most significant determinant of internal knowledge transfer in the MNC (e.g. Gupta and Govindarajan, 2000). When subsidiaries differ in their absorptive 
capacity, this affects the level of knowledge transfer from other MNC units (Cohen and Levinthal, 1990). While the literature offers multiple methods to conceptualise and operationalize absorptive capacity (Zahra and George, 2002), little attention has been paid to the question of whether and how firms can enhance the development of absorptive capacity through deploying knowledge management tools. With a few exceptions (e.g. Foss and Pedersen, 2002; Minbaeva et al, 2003) empirical studies treat absorptive capacity as given and as an exogenous determinant to knowledge processes. Little is known about how knowledge management tools influence absorptive capacity and how this impacts knowledge inflows and subsidiary performance.

Most empirical studies of knowledge processes on subsidiary level are based on surveys with only one informant (typically the CEO or another top-manager) from each organization/subsidiary. The implicit assumption behind this methodology is that perceptions on knowledge processes are so homogeneous inside the organization that one central informant can express "the average" perception of all members of the organization. This is a highly questionable assumption and in this paper is instead applied a unique data-set collected on the level of individuals that includes individual perceptions of the use of knowledge management tools, motivation, ability, knowledge inflows and subsidiary performance.

The contribution of this article is three-fold: 1) It introduces a model that treats subsidiary absorptive capacity as an endogenous construct in enabling knowledge inflows and enhancing performance on a subsidiary level. Of course, the message that absorptive capacity matters for knowledge inflows is hardly new (e.g., Cohen and Levinthal, 1990), but systematic theorizing and testing of knowledge tools as enablers of absorptive capacity are elusive; 2) While most studies have restricted their analyses to effects on knowledge flows to the neglect of its performance implications this article includes a direct test of performance implications of knowledge inflow on subsidiary level; and 3) On the methodology, a unique data-set including individual perceptions of knowledge processes from one single MNC HeidelbergCement - is applied to test the whole model including the managerial actions (Knowledge Management tools), the intermediary steps (developing absorptive capacity and increasing knowledge inflows) and the final outcome (subsidiary performance). 


\section{Theory and hypothesis}

Below, we pursue two arguments. The first argument relates to the conceptualisation and operationalisation of absorptive capacity on a MNC subsidiary level. We explain why absorptive capacity matters for intra-firm knowledge flows, and how levels of absorptive capacity can be influenced by the deployment of knowledge management tools. In this argument we picture absorptive capacity as the motivation and ability of subsidiary employees to deal with knowledge inflows, both may be actively influenced by management's selection of knowledge management tools. The second argument deals with the performance implications of knowledge inflows that are enabled through absorptive capacity. Is there any reason to expect that levels of knowledge inflows will vary in their effect on subsidiary performance? The following section develops our arguments to derive hypotheses as summarized in the following model.

Figure 1. The theoretical model

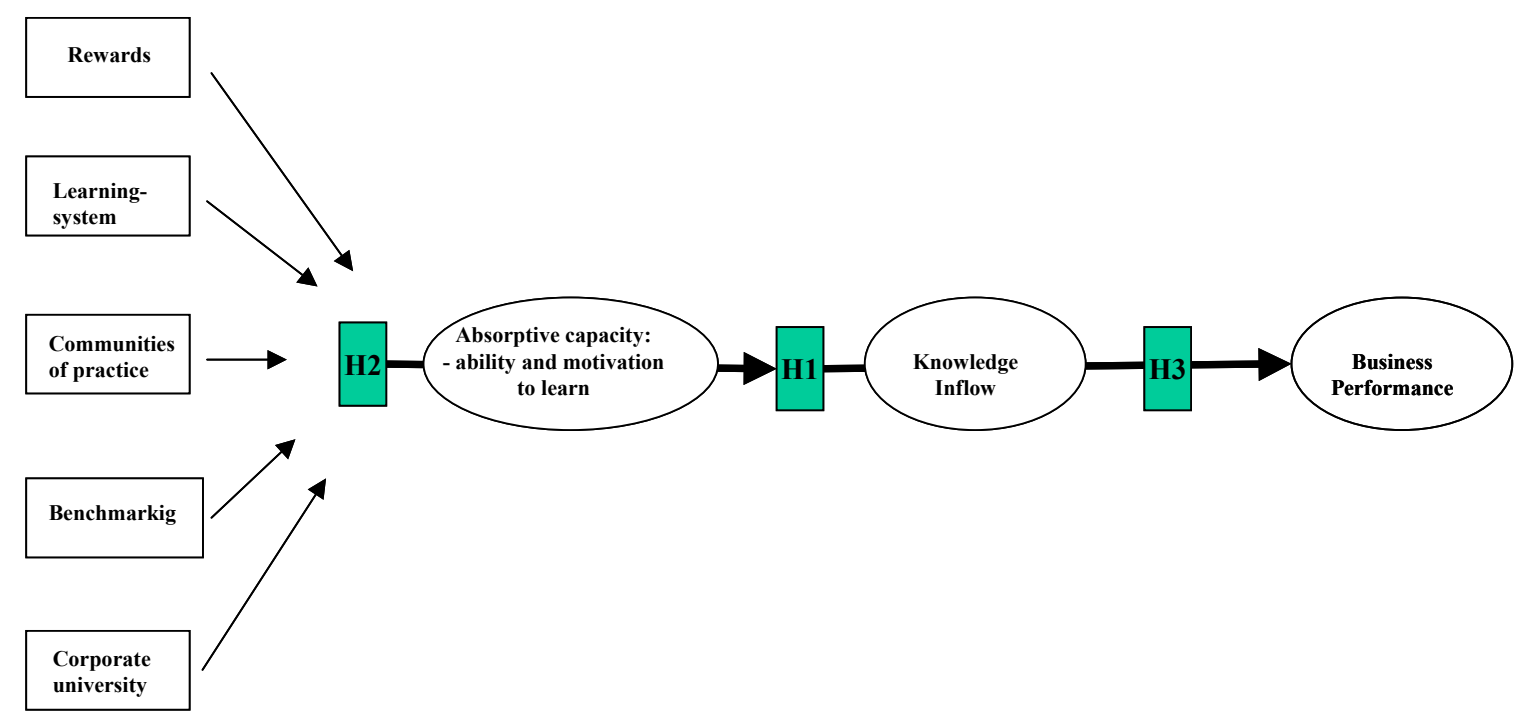

\section{Developing subsidiary absorptive capacity}

The concept 'absorptive capacity' has been mainly used to capture a company's ability to recognize, assimilate, and apply external knowledge to commercial ends (Cohen and Levinthal, 1990: 128). Extending the work of Lane and Lubatkin (1998), Lane, Salk and 
Lyles (2001) in their study on knowledge acquisition in international JV propose that "the first two components, the ability to understand external knowledge and the ability to assimilate it, are interdependent yet distinct from the third component, the ability to apply the knowledge" (p.1156).

Zahra and George (2002) criticised existing studies for applying measures (like R\&D intensity, number of scientists working in R\&D departments, etc.) that "have been rudimentary and do not fully reflect the richness of the construct" (p. 199). For example, current measures of absorptive capacity are focused on the absorption of knowledge in the MNC's external relations rather than on the absorption of knowledge from other subsidiaries in the MNC; they neglect the role of individuals in the organization, but their motivation and ability is crucial for knowledge utilization and exploitation. Furthermore, current measures may be too occupied with the ability to recognize and assimilate external knowledge (e.g. potential absorptive capacity) but neglect the role of the receiving unit's motivation to put knowledge to commercial use (e.g. realized absorptive capacity).

Addressing these critiques, Minbaeva et al (2003) identify the subsidiary's employees' ability and motivation as the key aspects of a subsidiary's absorptive capacity that in turn enables a subsidiary to benefit from internal knowledge flows. Clearly, when employees of a subsidiary lack the ability to understand and recognize knowledge of other units, for example because they are cognitively focussed in a specialized knowledge domain (March, 1991; Levinthal and March, 1993) a subsidiary's absorptive capacity will decline. Likewise, when employee's lack motivation to deal with new knowledge, --- for example due to the notinvented here syndrome, or because they face arcane, complicated, and time consuming social interaction with other units, --- the result may be knowledge-hostility between subsidiaries that negatively affects a subsidiary's absorptive capacity (Michailova and Husted, 2003). Conversely, if subsidiary employee's are both able and motivated with regards to acquiring external knowledge this indicates higher absorptive capacity and in accordance with Cohen and Levinthal, (1990) and Zahra and George (2002) we expect:

\section{H1: Higher absorptive capacity increases knowledge inflows}

While many empirical studies regard absorptive capacity as an exogenous construct to knowledge inflows, this study regards it as an endogenous construct subject to degrees of 
managerial discretion (see also Foss and Pedersen, 2002, Minbaeva et al, 2003). Here we consider different knowledge management tools, which may contribute to the development of the absorptive capacity. This allows us to examine the possible managerial influence on absorptive capacity that is not often examined in the literature. How do knowledge management tools employed at Heidelberger Cement including learning system, and communities of practice, corporate university, subsidiary benchmarking, and reward systems influence the subsidiary's employees' ability and motivation to utilise knowledge flows from other units in the MNC?

As suggested by much research on knowledge management (see Argote, 1999; Krogh et al, 2000 for a synthesis) learning systems need to provide access to other MNC unit's knowledge. Only when MNC employee's can identify valuable knowledge by searching topics or knowledgeable partner's in other MNC units without incurring substantial transaction costs (Mahnke and Venzin, 2003; Kautz and Mahnke, 2003) will they be able and motivated to utilize knowledge inflows. By contrast, when individual transaction costs of knowledge search and access are substantial, for example because adequate communication channels are missing (Pedersen et al, 2003), individual's motivation will decrease accordingly. To decrease transaction cost of knowledge inflows Heidelberger Cement deployed an intranet-solution which acts as facilitator for identifying experts and strategically important knowledge domains. In addition, expert teams identify leading practices in diverse knowledge areas such as energy efficiency, new concrete applications, and logistics to develop benchmarking reports that codify and document valuable knowledge created in leading subsidiaries so that other subsidiary's can improve their performance based on benchmarking.

While explicit knowledge sharing is enabled through benchmarking reports, the corporate university, and learning system, knowledge sharing in communities and teams complements such efforts, but tends to focus more on tacit knowledge exchange (LeonardBarton and Sensiper, 1998). Several forms of teamwork, including communities of practice are conducive to the integration and creation of knowledge in Heidelberger Cement (Wenger and Snyder, 2000). Interdisciplinary teams often integrate knowledge (Grant, 1996) that hitherto existed separately and dispersed across function in the MNC. Through interactive learning, community members develop community specific communication codes or combinative capabilities (Kogut \& Zander, 1993; Monteverde, 1995). Thus, by educating 
employees across subsidiary boundaries "communities of knowing" emerge, and through specific language codes their members increase their ability and motivation (Osterloh and Frey, 2000) to combine and blend a variety of knowledge across the MNC's subsidiaries.

Teamwork in communities does not only educate a subsidiary's employees, it also enhances their involvement and motivations to better utilise knowledge inflow's from other community members, which are employed at other subsidiaries. Through integrating knowledge of individual community members, teams may not only blend knowledge and insights beyond what individual members may achieve; new knowledge development may also be stimulated by conversations and language based learning in teams (e.g. Brown \& Duguid, 1991; Boland \& Tenkasi, 1995). Thus, teamwork also fuels knowledge creation resulting in "new combinations" across subsidiaries (Schumpeter 1934; Galunic and Rodan, 1998). In sum then, the analysis of communities of practice suggests that they influence a subsidiary's absorptive capacity through increasing the motivation and ability of subsidiary's employee's to share knowledge in social interaction.

Opinions on the influence of reward systems (both formal and informal) on the ability and motivation of a subsidiary's employees with regards to knowledge sharing remain divided. On the one hand, several authors argue the motivation for exchanging knowledge between subsidiaries cannot be easily influenced through explicit rewards (Osterloh and Frey, 2000; Krogh et al, 2000; Wenger and Snyder, 2000; Bartlett and Ghoshal, 1989; Ouchi, 1982). First, for explicit rewards to be effective motivators requires a sound measurement base (Ouchi, 1982). However, where input, output, or processes cannot be standardized and by implication easily measured, explicit incentives rewarding knowledge sharing behaviour of subsidiary employee's become easily arbitrary. This may be the case where knowledgesharing processes are surrounded by substantial causal ambiguity and uncertainty (Simonin, 1999). If so, providing explicit rewards on an arbitrary measurement base can lead to the perception of unfair incentives to crowd out intrinsic motivation of subsidiaries employee's (Osterloh and Frey, 2000).

In addition, when knowledge sharing behaviour is multidimensional in that it requires initiatives along several dimensions including active requests, networking, and building close social ties (Hansen, 1999) explicit rewards that focus on one dimension to the neglect of another may undermine motivation to engage in complementary activities (Holmström and Milgrom, 1991). By implication, knowledge sharing may rather strive if participants in 
horizontal knowledge flows between subsidiaries are intrinsically motivated by common goals (e.g. Ouchi, 1082; Osterloh and Frey, 2000). Thus, signalling (Spence, 1972) organizational support through informal acknowledgement may help intrinsic motivation without incurring the negative effects of misdirected extrinsic rewards.

On the other hand, employees take part in knowledge sharing only as long as the benefits exceed the costs; otherwise, they may withdraw. Accordingly, whenever possible increasing the employee's benefits through providing explicit rewards is appropriate. For example, when subsidiary employees' knowledge sharing behaviour can be specified in less uncertain and ambiguous knowledge exchange relation, providing explicit rewards alongside informal acknowledgements can increase motivation, in particular, if explicit rewards act as complement rather than as substitute to intrinsic motivation (Frey, 1997; Foss and Mahnke, 2003; Laursen and Mahnke, 2001). In addition, as shown by Mahnke and Venzin (2003) developing a measurement base for explicit rewards through monitoring by experts can also be seen as an investment to increase common shared knowledge between subsidiary employee's, which in turn increases the ability to share knowledge among them. In sum then, we expect that knowledge management tools act as antecedence to absorptive capacity defined as the motivation and ability of employee's to acquire new knowledge, thus:

H2: Learning system, communities of practice, corporate university, benchmarking, and reward-systems influence positively the absorptive capacity.

\section{Knowledge inflows and subsidiary performance}

A subsidiary's employees' may be able and motivated to acquire and assimilate knowledge from other MNC units, but might not have the capability to transform and exploit the knowledge to benefit the subsidiary's bottom line (e.g. Nelson and Winter, 1982; Hedlund, 1994; Szulanski, 2003). As a necessary condition, knowledge inflows must influence the receiving units employee's understanding as well as their behaviour and action (Fiol and Lyles, 1985). Only when knowing-doing gaps are closed can knowledge sharing among subsidiary's lead to cost reduction and innovation. For that purpose, the receiving unit often needs to adapt received knowledge to local circumstance, however (Hedlund, 1994). 
While the influence on individual's action is a minimum condition, knowledge sharing may benefit the receiving units through routine adaptation involving several individuals (Nelson, and Winter, 1982; Szulanski, 2003). For example, Nelson \& Winter (1982: 131) suggest that 'reliable routines of well understood scope' provide the best components for intra-firm replication of processes, and perhaps more importantly, new combination of routines for innovations. Nonaka and Takeuchi (1995) agree that knowledge inflow's among units involves the social processes of linking new knowledge to existing knowledge (e.g. about components or processes). In sum then, knowledge inflows may impact a subsidiary's performance through changing individual insights and behaviour, be it individually or embedded in organizational routines (e.g. Kim, 1993).

While knowledge sharing may contribute to value creation in a subsidiary, it has also its costs. For example, several authors suggest that these costs may be substantial and include time spent on knowledge sharing and adaptation, infrastructure investments etc (see for a review, Foss and Mahnke, 2003), as well as opportunity costs in terms of expenditures and cognitive capacity that could have been used to foster knowledge creation and process improvement internally to the focal subsidiary (Gammelgaard and Pedersen, 2003). Thus, being able and motivated to put knowledge from other MNC units to use is one thing. It may be quite another thing to benefit from knowledge inflows. Nonetheless, we expect:

\section{H3: Knowledge inflows influence positively a subsidiary's performance}

\section{Data and Method}

\section{Research Site and Data Collection}

The research was conducted in a German cement company, HeidelbergCement. With around 1'500 subsidiaries in over 50 countries, worldwide cement sales for over 6 billion Euro and 36,000 employees, HeidelbergCement is one of the four largest cement manufacturers in the world. During our study, the company entered in a consolidation phase after rapid expansion. HeidelbergCement grew from below 10'000 employees to the current size in less than 10 years, mainly through acquisitions. An objective of the gradual integration of the newly acquired companies was to increase the knowledge exchange between the different units. 
Although one site-sampling has disadvantages in terms of generalizability of results across sectors, it has advantages through controlling for contextual factors that complicate the interpretation of results in multiple-firm samples (i.e. variation in industry and firm-specific factors). In addition, previous research has successfully used single firm sampling to explore the effects of intra-firm networks on resource exchange and combination (Tsai and Ghoshal, 1998). Thus, we decided to limit our survey to one company, which allowed us to include more informants from each subsidiary. This is an advantage compared to most other studies that only include one informant from each organization and treat the perception of this informant as representative for the whole organization (e.g. Lane and Lubatkin, 1998; Gupta and Govindarajan, 2000).

We developed a questionnaire based on a literature review and following our first phase of 52 on-site interviews with senior mangers from the 6 business units of HeidelbergCement. The interviews ranged from 1 to 4 hours in length. We sent the survey to 10 subsidiary managers as a pilot run to increase the clarity of our questions and avoid interpretation errors. We discussed the face validity of the questions, which resulted in several substantial changes of the phrasing of the questions. After the survey pre-testing, we identified a sample of 265 leading MNC unit managers stemming from all geographical business areas of HeidelbergCement. The selected managers represented 3 distinct groups: the first group included 100 managers that had either been previously interviewed by our research team or participated in one of the international knowledge management initiative fostered by the MNC's headquarter. The second group consisted of 100 mangers that have not been interviewed and did not participate in knowledge management workshops. In addition, we included 65 engineers from the subsidiaries to make sure to get the views of the employees that are most directly involved in international day-to-day knowledge transfer.

The questionnaire was sent out to participants in paper form together with a 6-page brochure explaining the scope of the knowledge management initiatives at HeidelbergCement as well as a letter by the CEO supporting the survey. Participants had 4 weeks to return the questionnaire via mail or fax. This mailing process was managed by the headquarter's office. We collected 222 usable questionnaires - a response rate of $83,77 \%$. The fact that the participants had to indicate their names on the envelop of the survey most likely contributed to this high return rate. 


\section{Measures}

All data were collected through the questionnaire and most variables are multi-item measures that were measured using seven-point Likert scales. However, items such as the number of employees were measured using actual values. The following sections provide the exact wording used for questionnaire items.

Business performance. Several researchers have turned to perceptual measures of performance as better forward-looking measure of performance than more objective performance measures (e.g.) that capture past performance rather than future performance (e.g. Andersson et al., 2001). It has also been shown that perceptual measures tend to have a high correlation with objective accounting-based measures (Geringer and Hebert, 1991). Accordingly, we apply a perceptual measure of performance and our definition of business performance captures many dimensions of business performance including economic gains and product development. The respondents were asked to what extent the applied knowledge management initiatives in HeidelbergCement were expected to improve business results in terms of cost saving, additional revenue, process improvements, product improvements and new product and processes. Respondents indicated this on a seven-point Likert scale, where 1 was defined as "not important" and 7 was defined as "very important" for all the five abovementioned activities. Business Performance is a multi-item construct calculated as the average score reported by respondents across these five items (Alpha $=0.87$ ).

Inflow of knowledge. The construct of "Inflow of knowledge" captures the extent of inflow of knowledge from other units in HeidelbergCement to the focal unit. The construct was measured by asking respondents to assess to what extent does knowledge represented in other unit's influences your work, where 1 equaled "not at all" and 7 equaled "very strongly.

Absorptive Capacity. The construct of "absorptive capacity" captures both the individual perception of ability to learn and acquire new knowledge, and the motivation to do so. The ability to learn was measured by asking respondents to assess the following two statements "I perfectly understand the knowledge" and "I can easily acquire new knowledge". In order to measure the motivation to learn the respondents were asked to assess the following two statements "I find knowledge sharing rewarding" and "I don't fear they will steal my ideas" (reverse coded). All four statements were measured on a seven-point 
Likert scale, where 1 was defined as "never" and 7 was defined as "always". Taken together these four items measures the Absorptive Capacity as a multi-item construct. The construct was calculated as the average score reported by respondents across these four items (Alpha $=0.83)$.

Reward. This construct is capturing the perception of the individuals as to what extent the organization (HeidelbergCement) is rewarding individual knowledge activities. The perception of the rewarding system was measured by asking respondents to assess the following two statements "My efforts to create and share knowledge are rewarded formally" and "My efforts to create and share knowledge are rewarded informally". Both were measured on a seven-point Likert scale (1 equaled "don't agree" to 7 equaled "strongly agree") and the construct of rewarding was calculated as the average score of these two items (Alpha=0.63).

Learning culture. The construct of "learning culture" captures the individual perception of the openness towards knowledge sharing and the availability of needed knowledge in the organization. In order to measure the learning culture the respondents were asked to assess the following three statements "I know whom to ask when I need knowledge", "I know where to look when I need knowledge" and "I have easy access to communication channels" on a seven-point Likert scale (1 equaled "don't agree" to 7 equaled "strongly agree"). The construct of learning culture was calculated as the average score of these three items (Alpha $=0.71)$.

Corporate university. The construct of "corporate university" is capturing the individual perception of the importance of a knowledge management tool introduced by HeidelbergCement, namely a corporate university. The respondents were asked to assess the importance in terms of impact on: 1) personal field of activities, 2) business results, 3) knowledge sharing, and 4) knowledge creation. Our measure of the significance of Corporate university is based on the average of these four items (Alpha=0.82).

Group benchmark report. The construct of "group benchmark report" captures the individual perception of the importance of a knowledge management tool introduced by HeidelbergCement, namely group benchmark report. The respondents were asked to assess the importance in terms of impact on: 1) personal field of activities, 2) business results, 3) 
knowledge sharing, and 4) knowledge creation. Our measure of the significance of Group benchmark report is based on the average of these four items (Alpha=0.71).

Communities of practice. The construct of "communities of practice" captures the individual perception of the importance of a knowledge management tool introduced by HeidelbergCement, namely communities of practice. The respondents were asked to assess the importance in terms of impact on: 1) personal field of activities, 2) business results, 3) knowledge sharing, and 4) knowledge creation. Our measure of the significance of Communities of practice is based on the average of these four items (Alpha $=0.76)$.

Controls. To control for the characteristics of knowledge, particularly the codification vs. tacitness of knowledge, that have been identified as an important factor influencing the inflow of knowledge in other studies (e.g. Kogut and Zander, 1992; Szulanski, 1996; Simonin, 1999) we have measured the extent to which the organizational knowledge is represented in a codified vs. tacit form. The level of codification of organizational knowledge is measured by asking respondents to assess the following statements for knowledge represented in their unit "New employees can easily learn what we know", "Knowledge is extensively documented and well structured" and "Knowledge in our unit can be easily expressed". The three items are added together and the average of the three items are making up our construct, level of codification (Alpha=0.68).

Furthermore, two more control variables are related to the business performance. These are the extent to which the knowledge in the focal unit are formally acknowledged by other organizational units in HeidelbergCement (measured as a single item construct on a sevenpoint Likert scale where 1 equaled "not at all" and 7 equaled "to a high degree") and the extent to which knowledge from other units must be adapted in order to apply it in the context of the focal unit (measured as a single item construct on a seven-point Likert scale where 1 equaled "not at all" and 7 equaled "to a high degree"). We expect that formal acknowledgement of knowledge in the focal unit will have a positive impact on business performance, while required knowledge adaptation will have a negative impact on business performance. 


\section{Results}

\section{Tests of Hypotheses}

The hypotheses may be summarized in three basic models as follows.

1) Absorptive capacity $=$ Reward + Learning culture + Communities of practice + Group benchmark report + Corporate university + Error

2) Inflow of knowledge $=$ Absorptive capacity + Error

3) Business performance $=$ Inflow of knowledge + Error

However, since the above models represent decisions that are interdependent (i.e., they have to be considered jointly), the use of single equation models may yield biased results and obscure interesting theoretical possibilities. As the above models are interdependent, it is possible that the joint optimization of all involved variables may lead to sub-optimization of one or more individual variables. Statistically, the interdependence might be reflected in that error terms of the three models are somehow correlated. Hence, the correct model to estimate these decisions is a simultaneous equation model as three-stage least square, which circumvents the problem of interdependence by using instrument variables (often the exogenous variables) to obtain predicted values of the endogenous variables (in our case: knowledge inflow, and business performance).

The correlation matrix (including all correlation coefficients) and descriptive data (mean values, standard deviation, minimum and maximum values) on all variables in the model are provided in the Appendix 1. In order to detect potential problems of multicollinearity we should look at correlation coefficients among variables 1-5 (1. equation), variables 6-7 (2. equation) and variables 8-10 (3. equation). None of these are above the usual threshold indicated the possibility of multicollinearity (i.e. $r>0.5$ ), (Hair et al., 1995). However, the correlations between corporate university, communities of practice and group benchmark report gets close with coefficients 0.41-0.49. But, running the models with some of the correlated variables omitted had no effect on the explanatory power of the main variables. Therefore, we concluded that the results are very stable in terms of the different 
specifications of the model and the data doesn't seem to include problems of multicollenearity.

We have applied the three-stage least square regression techniques (3SLS) with instrument variables to test all hypotheses simultaneously. The result of the total model is reported in Table 1 and figure 2. Numbers in parentheses represent standard errors.

Table 1: The three-stage least squares estimation of a simultaneous equation model.

\begin{tabular}{|c|c|c|c|}
\hline & \multicolumn{3}{|c|}{ Equations } \\
\hline & $\begin{array}{l}\text { ABSORPTIVE } \\
\text { CAPACITY }\end{array}$ & $\begin{array}{l}\text { INFLOW OF } \\
\text { KNOWLEDGE }\end{array}$ & $\begin{array}{l}\text { BUSINESS } \\
\text { PERFORMANCE }\end{array}$ \\
\hline Intercept & $\begin{array}{c}0.77^{*} \\
(0.45) \\
\end{array}$ & \begin{tabular}{|c|}
1.81 \\
$(1.17)$ \\
\end{tabular} & \begin{tabular}{|l|}
0.11 \\
$(0.86)$ \\
\end{tabular} \\
\hline Reward & $\begin{array}{c}0.03 \\
(0.03) \\
\end{array}$ & & \\
\hline Learning culture & $\begin{array}{r}0.09^{*} \\
(0.05) \\
\end{array}$ & & \\
\hline Communities of practice & $\begin{array}{l}0.17^{* * *} \\
(0.06)\end{array}$ & & \\
\hline Group benchmark report & $\begin{array}{l}0.11^{* * *} \\
(0.04)\end{array}$ & & \\
\hline Corporate university & $\begin{array}{l}0.09^{* *} \\
(0.04) \\
\end{array}$ & & \\
\hline Absorptive capacity & & $\begin{array}{l}1.10^{* * *} \\
(0.34)\end{array}$ & \\
\hline Codification of knowledge & & $\begin{array}{l}-0.07 \\
(0.05)\end{array}$ & \\
\hline Inflow of knowledge & & & $\begin{array}{l}0.94^{* * *} \\
(0.19)\end{array}$ \\
\hline Formal acknowledgement & & & $\begin{array}{l}0.01 \\
(0.05)\end{array}$ \\
\hline Knowledge adaptation & & & $\begin{array}{l}0.06 \\
(0.04)\end{array}$ \\
\hline $\begin{array}{l}\text { F-value } \\
\text { R-square } \\
\mathrm{N}\end{array}$ & $\begin{array}{l}4.18^{* * *} \\
222\end{array}$ & $\begin{array}{l}8.73^{* * *} \\
222\end{array}$ & $\begin{array}{l}6.85^{* * *} \\
0.25 \\
222\end{array}$ \\
\hline
\end{tabular}

${ }^{* * *},{ }^{* *}$ and ${ }^{*}=$ significant at 1,5 and 10 percent, respectively.

Overall, the system of the three equations (models) works well, with a system weighted $\mathrm{R}$-square of 0.25 . This indicates that almost one fourth of the observed variation in the business performance is explained by the variables in the model. We turn now to the tests of our explanatory hypotheses. 
As shown in Table 1 three knowledge management tools of group benchmark report (p $<1 \%$ ), communities of practice $(\mathrm{p}<1 \%$ ) and corporate university $(\mathrm{p}<5 \%$ ) have a significantly positive impact on the development of absorptive capacity in the focal unit. The same is true for the learning culture $(\mathrm{p}<10 \%)$ that is positively facilitating the absorptive capacity. However, the reward turns out to be insignificant (but with the expected positive sign). The results indicate that there is managerial discretion in developing the absorptive capacity, however, some knowledge management tools and incentive structures will have a stronger effect than others. A more explicit reward system (extrinsic motivation) seems to be of less value in the development of absorptive capacity, while learning culture and the knowledge management tools like group benchmark report and corporate university seems to have a strong positive impact. This is in line with the expanding literature on intrinsic vs. extrinsic motivation in knowledge management (e.g. Osterloh and Frey, 2000).

Furthermore, as expected absorptive capacity have a strong positive impact $(\mathrm{p}<1 \%)$ on the inflow of knowledge from other units and this is true even when controlling for the level of codification (turned out to be insignificant in itself). And the inflow of knowledge has a very strong positive impact $(\mathrm{p}<1 \%$ ) on business performance, while both the two control variables turned out to become insignificant.

Figure 2. The empirical model with significant coefficients

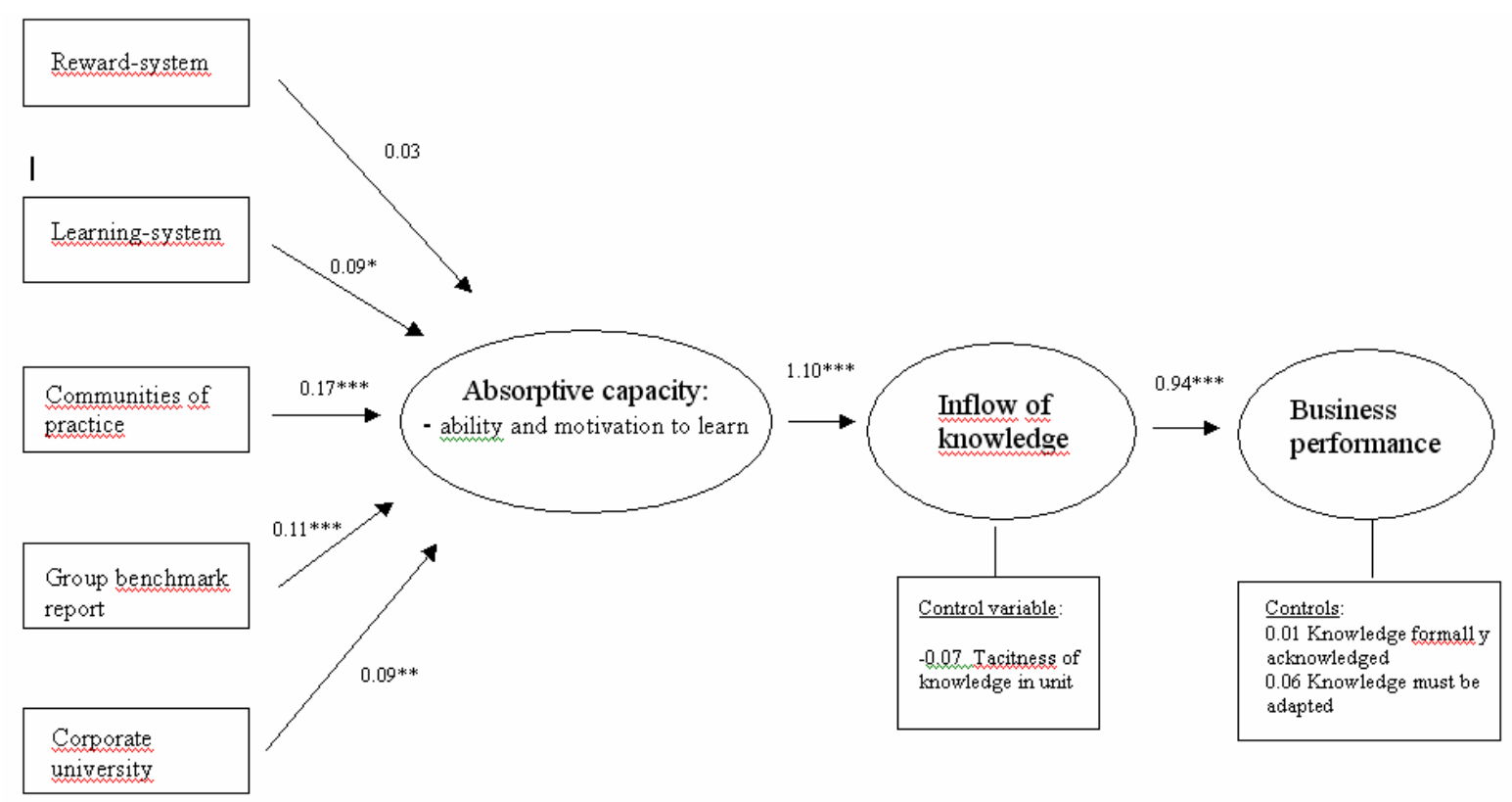


The advantage of the model is that it establishes a link between the individual knowledge activities and the business performance, where business performance is defined as a multi-dimensional construct capturing not only the efficiency gains but also production and product developments. The model shows that there is a strong link between the microprocesses of setting up incentive structures and applying knowledge management tools through managerial action on the level of the unit and the business performance. The link goes through the development of absorptive capacity and the stimulation of knowledge inflow from other units.

\section{Discussion and Conclusion}

This study produced major evidence for the contention that deployment of knowledge management tools has important implications for the performance of MNC subsidiaries. Applying theory on knowledge flows and conceptualizing absorptive capacity as the ability and motivation to learn from new knowledge on the subsidiaries level, we found that knowledge management tools impact a subsidiary's absorptive capacity. Importantly, results indicated that absorptive capacity is subject to managerial discretion because knowledgemanagement tools, such as group benchmarking, communities of practice, learning culture etc, significantly influence levels of absorptive capacity. We showed also, that absorptive capacity influences knowledge inflows, which significantly influence subsidiary performance, thus eliminating doubts about their causal impact. This study showed that the application of knowledge management tools could be an important source of competitive advantage in the MNC, especially when they increase the ability and motivation of the subsidiary employees to utilize knowledge inflows from other units.

These findings can be juxtaposed against two prominent strands of research. Empirical research on knowledge flows has investigated impediments and facilitators of knowledge flows in firms, but is interested mainly in whether and to what degrees knowledge has been transferred given particular constellations of impediments and facilitating factor. Knowledge transfer, however, is costly and knowledge management tools deployed may be seen as an investment to increase business performance on several dimension. Thus, to examine the 
performance impact of knowledge management it is not enough to examine whether knowledge has been transferred. The current study is, to the best of our knowledge, the first to investigate not only antecedence of, but also the impact of knowledge flows on subsidiary performance. Clearly, researchers should no longer treat performance of knowledge management as an assumption and black box. Rather, opening the black box to unpack the relation between knowledge management tools employed, the knowledge flows they enable, and their impact on business performance does constitute an important area of future research.

The present study has obvious affinity to recent research on absorptive capacity. In general our findings support the assertion that absorptive capacity facilitates knowledge inflows. In contrast to prior empirical studies that seek to investigate knowledge absorption between firms, the current study was interested in intra-firm knowledge flows between MNC subsidiaries. Accordingly, following Minbaeva et al (2003) we conceptualized a subsidiary's absorptive capacity and developed measures to capture the ability and motivation of employees to learn from other units in the MNC. Clearly, absorptive capacity defined and measured this way opens new avenues for further research on how antecedence influence absorptive capacity, and how it impacts knowledge flows in both internal and external relations of the MNC.

Weaknesses in the present study provide some suggestions for future research. First, prospective research could explore whether and how a subsidiary's motivation and ability to learn does influence a subsidiary's knowledge sharing behavior. Often subsidiaries receive knowledge inflows based on their own knowledge sharing behavior with other units (Gupta and Govindarajan, 1991, 2000). An important question of future research could be to investigate knowledge inflows and outflows of focal MNC units simultaneously.

Second, future research could also distinguish between intra-firm and inter-firm sources of knowledge flows to assess their impact on business performance. For instance, the performance impact of knowledge flows might differ if sources of knowledge are external rather than internal to the MNC. The current study did focus on internal sources of knowledge flows only but neglected external knowledge inflows that figure so importantly in MNC research (e.g. Cantwell and Mudambi, 2003). 
Lastly, future research could empirically uncover the importance of alternative control mechanisms on the impact of knowledge inflows and outflows on a subsidiary level. The present study dealt with selected knowledge management tool that influenced the focal subsidiaries absorptive capacity. While our findings indicate managerial discretion in building absorptive capacity through knowledge management tool, somewhat surprisingly, we have not found strong support on the impact of reward systems on absorptive capacity. By exploring different types of extrinsic and intrinsic motivators (e.g. Osterloh and Frey, 2000), future research could investigate under what conditions these influence positively the ability and motivation of subsidiary employees to absorb and effectively utilize knowledge flows from internal and external sources to increase performance. 


\section{References}

Andersson, U., M. Forsgren \& U. Holm. 2002. The strategic impact of external networks: Subsidiary performance and competence development in the multinational corporation. Strategic Management Journal, 23 (11): 979-998

Andersson, U., M. Forsgren \& T. Pedersen. 2001. Subsidiary performance in multinational corporations: the importance of technology embeddedness. International Business Review, 10: 3-23.

Argote, L. 1999. Organizational learning: Creating, retaining and transferring knowledge. Norwell, MA: Kluwer.

Bartlett, Christopher \& Sumantra Ghoshal. 1989. Managing Across Borders. Boston: Harvard Business School Press.

Boland, R. J. \& Tenkasi, R.V. 1995. Perspective making and perspective taking in communities of knowing. Organization Science, 6: 350-372.

Brown, J.S. \& Duguid, P. 1991. Organizational learning and communities-of-practice: Towards a unified view of working, learning, and innovation. Organization Science, Vol. 2, No. 1, February, 40 - 57.

Cantwell, J. \& R. Mudambi. 2003. Multinational enterprises and competence-creating knowledge flows: A theoretical analysis. In: Mahnke \& Pedersen, Knowledge Flows, Governance, and the Multinational Enterprise - Frontiers in international Management Research. Palgrave Macmillan. Forthcoming.

Cohen, Wesley M. \& Daniel A. Levinthal. 1990. Absorptive Capacity: a New Perspective on Learning and Innovation. Administrative Science Quarterly, 35:128-152

Fiol, Marlene C. \& Marjorie A. Lyles. 1985. Organizational Learning. Academy of Management Review, 10(4): 803-813

Foss, $\mathrm{N}$ and V. Mahnke. 2003. Knowledge management: What can organizational economics contribute? In: Lyles, M and Esterby, M. (2003) Handbook of organizational learning and knowledge management: 78-103. Blackwell Publisher.

Foss, Nicolai \& Torben Pedersen. 2002. Transferring Knowledge in MNCs: The Roles of Sources of Subsidiary Knowledge and Organizational Context. Journal of International Management, 8: 1-19.

Frey, B. 1997. Not just for money. A Personal Theory of Motivation. Edward Elgar

Galunic, D. C., \& Rodan, S. 1998. Resource re-combinations in the firm: Knowledge structures and the potential for Schumpeterian innovation. Strategic Management Journal, 19: 1193-1201.

Gammelgard, J., U. Holm \& T. Pedersen.2003. The Dilemmas of MNC Subsidiary Transfer of Knowledge. In: Mahnke \& Pedersen, Knowledge Flows, Governance, and the Multinational Enterprise - Frontiers in international Management Research. Palgrave Macmillan. Forthcoming.

Geringer, J. M. \& L. Hebert (1991). Measuring performance of international joint ventures. Journal of International Business Studies, 22(2), 249-263.

Grant, R.M. (1996). Toward a Knowledge-Based Theory of the Firm. Strategic Management Journal, 17(special issue):109-22.

Gupta, A.K. and Govindarajan, V. (1991). Knowledge flows and the structure of control within multinational firms. Academy of Management Review, 16(4): 768-792.

Gupta, A.K. and Govindarajan, V. (2000). Knowledge flows within multinational corporations. Strategic Management Journal, 21(4): 473-496. 
Hansen, M. T. 1999. The search transfer problem: The role of weak ties in sharing knowledge across organizational subunits. Administrative Science Quarterly 44: 82111.

Hedlund, G. 1994. A model of knowledge management and the n-form corporation. Strategic Management Journal, 15: 73 - 90.

Holm, Ulf \& Torben Pedersen. 2000. The Emergence and Impact of MNC Centres of Excellence. London: Macmillan Press.

Holmström, B. \& Milgrom, P. 1991. Multitask principal-agent analyses: Incentive contracts, asset ownership, and job design, Journal of Law, Economics, and Organization 7: 2452.

Kautz. K. and V. Mahnke. 2003. Value Creation through IT-supported Knowledge Management? The Utilisation of a Knowledge Management System in a Global Consulting Company. Informing Science 6: 75-88.

Kim, D. H. 1993. The link between individual and organizational learning. Sloan Management Review 35, 1: 37-49.

Kogut, B. \& Zander, U. 1993. Knowledge of the firm and the evolutionary theory of the multinational corporation. Journal of International Business Studies, 24: 625-645.

Kogut, B., \& Zander, U. 1992. Knowledge of the firm, combinative capabilities, and the replication of technology. Organization Science, 3: 383-397.

Krogh, G. von, Ochijo, K , Nonaka I., Enabling Knowledge Creation, Oxford University Press, 2000.

Lane, Peter \& Michael Lubatkin. 1998. Relative Absorptive Capacity and Interorganizational Learning. Strategic Management Journal, 19(5): 461-477

Lane, Peter, Jane E. Salk \& Marjorie A. Lyles. 2001. Absorptive Capacity, Learning and Performance in International Joint Ventures. Strategic Management Journal, 22(12): $1139-1161$.

Laursen K. and V. Mahnke, 2001. Knowledge strategies, innovative capacity and complementarity in human resource practices. Journal of Management and Governance 1: 1-27.

Leonard-Barton, D. \& Sensiper, S. 1998. The role of tacit knowledge in group innovation. California Management Review 40/3: 112-132.

Levinthal, D. A., \& March, J. G. 1993. The myopia of learning. Strategic Management Journal 14: 95-113.

Lyles, Marjorie A. \& Jane E. Salk. 1996. Knowledge Acquisition from Foreign Partners in International Joint Ventures. Journal of International Business Studies, 27(5): 877904

Mahnke, V. and M. Venzin (2003) Governing knowledge teams in the MNC. Management International Review: forthcoming

March, J. G. 1991. Exploration and exploitation in organizational learning. Organization Science, 2: 71-87.

Michailova, S., \& K. Husted. 2003. Knowledge-sharing hostility in Russian firms. California Management Review. Berkeley, 45 (3): 59-81.

Minbaeva, D., T. Pedersen, I. Björkman, C. Fey and H.J. Park (2003). MNC Knowledge Transfer, Subsidiary Absorptive Capacity and HRM. Journal of International Business Studies, forthcoming.

Monteverde, K. 1995. Technological dialog as incentive for vertical integration in the semi conductor industry, Management Science, 41: 1624-16-1638. 
Nelson, R. \& Winter, S. 1982. An evolutionary theory of economic change. Cambridge, MA: The Belknap Press.

Nonaka, I. \& H. Takeuchi. 1995. The knowledge creating company. Oxford University Press.

Osterloh. M. and B. Frey, 2000. Motivation, knowledge transfer and organizational forms. Organization Science, 11(5): 538-550.

Ouchi, W. G. 1982. Markets, Bureaucracies, and Clans Administrative Science Quarterly, 25, 129-141.

Pedersen, T., B. Petersen \& Deo Sharma (2003). Knowledge Transfer Performance of Multinational Companies. Management International Review, forthcoming.

Schumpeter, J.A. 1934. The Theory of Economic Development. Cambridge, MA: Harvard Press.

Simonin, Bernard L. 1999. Transfer of Marketing Know-How in International Strategic Alliances: an Empirical Investigation of the Role and Antecedents of Knowledge Ambiguity. Journal of International Business Studies, 30(3): 463-490

Spence, A. M. 1972. Job market signalling. Quarterly Journal of Economics, 87. 355-77.

Szulanski, Gabriel. 1996. Exploring Internal Stickiness: Impediments to the Transfer of Best Practice within the Firm. Strategic Management Journal, 17(Winter): 27-43.

Szulanski, G. 2003. Adaptation of know how for cross-border transfer. Management International Review: forthcoming

Tsai, W. and S. Ghoshal. (1998). Social capital and value creation: The role of intrafirm networks. Academy of Management Journal, 41(4); 464-477.

Wenger E. and Snyder W. 2000. Communities of Practice: The Organizational Frontier, Harvard Business Review: 78(1): 139-145.

Zahra, Shaker. A. \& Gerard George. 2002. Absorptive Capacity: a review, reconceptualization, and extension. Academy of Management Review, 27(2): 185-203 
Appendix 1. Correlation matrix for all variables included in the model $(\mathrm{N}=222)$

$\begin{array}{lllllllllll}1 & 2 & 3 & 4 & 5 & 6 & 7 & 8 & 9 & 10 & 11\end{array}$

1) Reward

2) Learning culture

3) Communities of practice

4) Group benchmark report

5) Corporate University

6) Absorptive capacity

7) Codification of knowledge

8) Inflow of knowledge

9) Formal acknowledgement

10) Knowledge adaptation

11) Business performance

Mean

Std. Dev.

Min. values

Max values
1.00

$0.29^{* * *} \quad 1.00$

$0.10 \quad 0.15^{* *} \quad 1.00$

$0.12 * \quad 0.17 * * \quad 0.41 * * * \quad 1.00$

$0.15^{* *} \quad 0.19^{* * *} \quad 0.45^{* * *} \quad 0.49^{* * *} \quad 1.00$

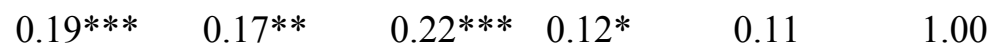

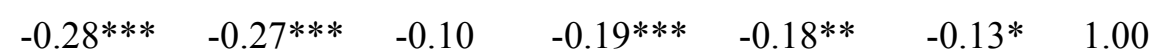

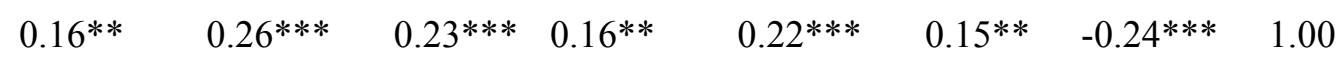

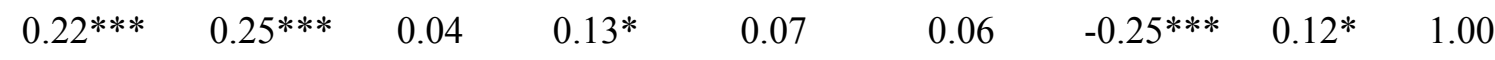

$\begin{array}{llllllllll}-0.05 & -0.03 & 0.12 * & 0.05 & 0.05 & -0.04 & -0.15^{* *} & 0.05 & 0.08 & 1.00\end{array}$

$0.06 \quad 0.14 * * \quad 0.47 * * * 0.60 * * * \quad 0.56 * * * \quad 0.10 \quad-0.14 * * \quad 0.20 * * * \quad 0.13 * \quad 0.13 * \quad 1.00$

$\begin{array}{lllllllllll}3.74 & 5.37 & 5.29 & 4.76 & 5.05 & 3.23 & 4.17 & 5.05 & 4.32 & 3.94 & 5.06\end{array}$

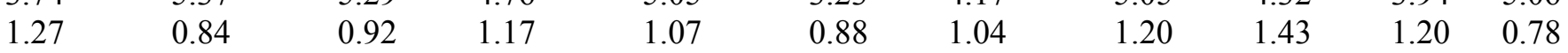

$\begin{array}{lllllllllll}1 & 2.66 & 2.25 & 1.75 & 1 & 1 & 1 & 2 & 1 & 1 & 2.13 \\ 7 & 7 & 7 & 7 & 7 & 7 & 6.33 & 7 & 7 & 7 & 7\end{array}$

$* * *, * *$ and $*$ indicates $1 \%, 5 \%$ and $10 \%$ significance level, respectively 